УДК 665.613: 543.57

\title{
ХАРАКТЕРИСТИКА ТЕРМИЧЕСКОЙ УСТОЙЧИВОСТИ МАСЕЛ ПРИРОДНЫХ БИТУМОВ И НЕФТЕЙ
}

\author{
Антипенко Владимир Родионович', \\ avr@ipc.tsc.ru
Баканова Ольга Сергеевна', olgapushkar@mail.ru \\ Кашапов Роман Сергеевич², \\ KashapovRS@tomsknipi.ru \\ ' Институт Химии нефти СО РАН, \\ Россия, 634055, Томск, пр. Академический, 4. \\ 2 ОАО «ТомсКНИПИнефть», \\ Россия, 634027, Томск, пр. Мира, 72.
}

\begin{abstract}
Актуальность исследования обусловлена тем, что термическая деструкция является одним из самых распространенных процессов переработки нефтяных остатков, тяжелых нефтей и природных битумов. Термические и термокаталитические процессы конверсии перечисленного углеводородного сырья сопровождаются образованием при термодеструкции смолисто-асфальтеновых веществ исходных объектов дополнительного количества дистиллятных фракций («вторичных» масел). Одновременно происходят процессы превращения масел исходного объекта и «вторичных» масел при температурах, соответствующих термической деструкции «слабых» и «прочных» связей в соединениях, входящих в их состав. При выборе оптимальных режимов термической и термокаталитической переработки тяжелого нефтяного сырья должны учитываться результаты оценки термической устойчивости содержащихся в них компонентов. Одним из методов изучения термической стабильности органического вещества осадочных пород является пиролитический анализ в варианте Rock-Eval. Сведения о возможностях этого метода для анализа масел весьма ограничены. В то же время из пирограммы масел можно получить информацию об их термической устойчивости и характеристических температурах деструкции содержащихся в них компонентов. А также получить информацию о различии этих параметров для масел, выделенных из нефтей и природных битумов, отобранных в различных нефтегазоносных провинциях и существенно отличающихся своим компонентным составом

Цель: сравнительный анализ с использованием метода Rock-Eval параметров термической устойчивости масел, выделенных из природных битумов и нефтей, отличающихся суммарным содержанием смолисто-асфальтеновых веществ, а также продуктов их лабораторной биодеградации и конверсии в сверхкритической воде.

объекты: масла, выделенные из 18 образцов нефтей и природных битумов, продуктов их лабораторной биодеградации и конверсии в сверхкритической воде.

Методы: анализ элементного состава, ЯMP'ㄱ-спектроскопия, пиролитический анализ в варианте Rock-Eval.

Результаты. Показано, что методом Rock-Eval можно получить информацию о термической устойчивости масел, выделенных из нефтей и природных битумов, отобранных в различных нефтегазоносных провинциях и отличающихся компонентным составом. Пирограммы масел содержат три пика, проявляющихся в различных интервалах температур. Пик 51 (изотерма $180{ }^{\circ} \mathrm{C}$ ) соответствует процессу испарения бензиновой фракции (HK...180 드. Пик S2a $\left(180 \ldots 350^{\circ} \mathrm{C}\right)$ соответствует наложению процесса испарения «средних» фракций масел и деструкции "слабых» C-S, C-O связей в структурных фрагментах их компонентов. Пик S2b $\left(350 \ldots 550^{\circ} \mathrm{C}\right)$ соответствует наложению испарения «высококипящих» компонентов масел и деструкции «прочных» С-О, С-С связей в их структурных фрагментах. Изученные образцы более чем на порядок (от 0,32 до 3,91) различаются отношением выхода летучих продуктов при $350 \ldots 550$ и $180 \ldots 350{ }^{\circ} \mathrm{C}\left(S_{2 b} / S_{2 a}\right)$, а также отношением выхода бензиновой фракции масел $-S_{1}$ и $\left(S_{2 b}+S_{2 a}\right)$ (от 0,044 до 0,518). Изученные образцы масел также различаются температурой максимальной скорости выхода углеводородов в процессе пиролиза в области пика S2b (от 445 до $466^{\circ} \mathrm{C}$ ) и более существенно в области пика S2a (от 292 до $350{ }^{\circ} \mathrm{C}$ ).
\end{abstract}

\section{Ключевые слова:}

Нефти, природные битумы, масла, выделение, состав, Rock-Eval-анализ, термическая устойчивость.

\section{Введение}

Промышленные процессы термической и термокаталитической конверсии тяжелых нефтей, природных битумов и их остаточных фракций $[1,2]$ сопровождаются образованием при термодеструкции смолисто-асфальтеновых веществ (САВ) исходных объектов дополнительного количества дистиллятных фракций («вторичных» масел). Одновременно происходят процессы превращения масел исходного объекта и «вторичных» масел при температурах, соответствующих термической деструкции «слабых» и «прочных» связей в соединениях, входящих в их состав. В [3, 4] выявлено за- метное изменение относительного содержания и состава гопанов, алкилбензолов, нафталинов, дибензотиофенов в летучих продуктах флэш-пиролиза масел нефтей и природного асфальтита при изменении температуры от $300 . . .400$ до $650{ }^{\circ} \mathrm{C}$. Эти результаты свидетельствуют о наличии в маслах высокомолекулярных образований, в которых перечисленные соединения находятся в виде ковалентно связанных структурных фрагментов. Дополнительные аргументы в пользу этого вывода были получены в $[5,6]$ при использовании селективных химических реакций для разрыва сульфидных и эфирных мостиков в компонентах масел 
природного битума (мальты) Ашальчинского месторождения. Анализ полученных продуктов методом хроматомасс-спектрометрии позволил установить, что алкилтриметилбензолы, алкилциклогексаны, хейлантаны, гопаны и фенантрены присутствуют в маслах этого битума не только в молекулярной форме, но частично в виде химически связанных структурных фрагментов в составе сложных высокомолекулярных образований. Структурные фрагменты в таких образованиях, по-видимому, могут быть связаны не только через сульфидные и эфирные мостики, но и полиметиленовыми цепочками.

Учитывая различия в энергии разрыва соответствующих связей: для $\mathrm{S}-\mathrm{S}$ и $\mathrm{C}-\mathrm{S}$ связей -226 и 272 кДж/моль, соответственно, для $\mathrm{C}-\mathrm{C}$ и $\mathrm{C}-\mathrm{O}$ связей - 348 и 358 кДж/моль, соответственно [7], можно предполагать, что при термическом воздействии их разрыв будет происходить при различных температурах. Одним из методов изучения термической стабильности органических веществ является пиролитический анализ.

Пиролитический анализ в варианте Rock-Eval, впервые предложенный в [8], широко применяется для оценки нефтегазогенерационного потенциала осадочных пород, характеристики термической устойчивости нерастворимого органического вещества пород (керогена), а также битумоидов и выделенных из них САВ [9-17]. Сущность этого метода - фиксация с использованием пламенно-ионизационного детектора количества летучих органических веществ (углеводородов), образующихся из исследуемого образца при его нагреве в токе инертного газа (гелия или азота) в открытой пиролитической системе. В зависимости от целей и исходных образцов, Rock-Eval анализ проводят в различных температурных программах (циклах).

При исследовании осадочных пород считается, что при нагреве до температуры $300{ }^{\circ} \mathrm{C}$ происходит термическая десорбция органических соединений, присутствующих в образце в свободном, адсорбированном или связанном лабильными химическими связями состоянии (пик $S 1$ ). При температурах от 300 до $650{ }^{\circ} \mathrm{C}$ совместно происходит испарение летучих более высокомолекулярных органических соединений и термическая деструкция смол, асфальтенов и керогена (нерастворимого органического вещества) с образованием летучих органических веществ (углеводородов), что отражается на пирограмме в виде одного (пик $S 2$ ) или двух пиков (пики $S 2$ а и $S 2 b)$. Кроме выхода углеводородов в области перечисленных пиков, важной характеристикой образцов является температура максимальной скорости выхода углеводородов в процессе пиролиза (TpS2 или $T_{\max }$ ), соответствующая максимуму пика $S 2(S 2 b)$ [16]. Применительно к керогену осадочных пород она характеризует степень его термической зрелости. Оценка термической зрелости ОВ пород также может быть проведена по значению этого параметра у асфальтенов, выделенных из битумоидов или нефтей [17].
Сведения о возможностях метода Rock-Eval для анализа масел весьма ограничены [3, 4]. В частности, показано, что пирограммы масел похожи на пирограммы смол, а именно, содержат три пика: пик $S 1$ и два пика $S 2$ и и $S 2$ b с максимумами в области $\sim 350$ и $450{ }^{\circ} \mathrm{C}$, соответственно. Так же как в случае керогена и САВ, появление первого пика $S 1$ на пирограмме масел соответствует испарению легких углеводородов при изотермическом режиме $\left(\sim 150 \ldots 20{ }^{\circ} \mathrm{C}\right)$. Появление двух других пиков при дальнейшем нагреве масел обусловлено образованием дополнительного количества летучих органических веществ при деструкции некоторых компонентов, содержащихся в них.

Можно считать, что положение максимумов пиков $S 2 \mathrm{a}$ и $S 2 \mathrm{~b}$ на шкале температуры (TpS2a, $T p S 2 b)$ в пирограмме отражает энергию разрыва «слабых» и «прочных» связей в компонентах масел, а интенсивность пиков характеризует относительное содержание соответствующих компонентов. Другими словами, из пирограммы масел можно получить информацию об их термической устойчивости и характеристических температурах деструкции содержащихся в них компонентов.

Цель настоящей работы - сравнительный анализ с использованием метода Rock-Eval термической устойчивости масел, выделенных из природных битумов и нефтей, отличающихся суммарным содержанием САВ, а также продуктов их лабораторной биодеградации и конверсии в сверхкритической воде.

\section{Экспериментальная часть}

В качестве объектов исследования были выбраны масла, выделенные из природных битумов и нефтей, отобранных в различных нефтегазодобывающих областях и провинциях (табл. 1). Были изучены также масла продуктов биодеградации ашальчинской мальты в лабораторных условиях [18] и конверсии Ивановского асфальтита в сверхкритической воде (СКВ) [19]. Масла выделены из исходных объектов по методике, представленной в [20]. Методика включает осаждение асфальтенов 40-кратным избытком гексана, последующее разделение деасфальтенизата адсорбционной хроматографией на силикагеле на масла, элюированные смесью гексана и бензола (70:30 по объему) и этанол-бензольные смолы, элюированные смесью этанола и бензола (50:50 по объему).

Выделенные из перечисленных исходных объектов масла были охарактеризованы методами элементного анализа, ЯМР ${ }^{1} H$-спектроскопии, пиролитического анализа в варианте Rock-Eval.

Спектры ЯМР ${ }^{1} \mathrm{H}$ регистрировали с помощью ЯMР-Фурье спектрометра AVANCE AV 300 фирмы «Bruker» при $300 \mathrm{MГц} \mathrm{в} \mathrm{растворах} \mathrm{CDCl}_{3}$, химические сдвиги сигналов приведены относительно тетраметилсилана. Относительное содержание атомов водорода в различных структурных фрагментах определяли исходя из площадей сигналов в соответствующих областях спектра [21]. $H_{\text {ar }}(8,3 \ldots 6,6)$, 
$H_{\text {ol }}(6,6 \ldots 4,5), H_{\alpha}(4,1 \ldots 2,1), H_{\beta}(2,1 \ldots 1,1), \quad H_{\gamma}$ $(1,1 \ldots 0,3)$ м. д., где $H_{\text {ar }}$ - доля протонов у ароматических атомов углерода; $H_{\text {ol }}$ - доля олефиновых протонов в алифатических фрагментах молекул; $H_{\alpha}$ - доля протонов у атома углерода в $\alpha$-положении алифатических заместителей ароматических структур; $H_{\beta}$ - доля протонов в метиленовых группах алифатических фрагментов молекул; $H_{\gamma}$ - доля протонов в терминальных метильных группах алифатических фрагментов молекул.

Таблица 1.Наименование и районы отбора нефтей и природных битумов

Table 1. Regions of sampling of crude oils and natural bitumens

\begin{tabular}{|c|c|c|c|}
\hline $\begin{array}{l}\text { Образец } \\
\text { Sample }\end{array}$ & $\begin{array}{c}\text { НГО, НГП } \\
\text { Oil-and-gas re- } \\
\text { gion or province }\end{array}$ & $\begin{array}{l}\text { Образец } \\
\text { Sample }\end{array}$ & $\begin{array}{c}\text { НГО, НГП } \\
\text { Oil-and-gas re- } \\
\text { gion or province }\end{array}$ \\
\hline $\begin{array}{l}\text { Оленекский } \\
\text { acфальт } \\
\text { Oleneksky } \\
\text { asphalt }\end{array}$ & $\begin{array}{l}\text { Лено- } \\
\text { Вилюйская } \\
\text { Lena-Vilyusk }\end{array}$ & $\begin{array}{l}\text { Русская нефть } \\
\text { Russkaya oil }\end{array}$ & $\begin{array}{l}\text { Западно- } \\
\text { Сибирская } \\
\text { West Siberian }\end{array}$ \\
\hline $\begin{array}{l}\text { Ивановский } \\
\text { асфальтит } \\
\text { Ivanovsky } \\
\text { asphaltite }\end{array}$ & $\begin{array}{l}\text { Волго- } \\
\text { Уральская } \\
\text { Volga-Ural }\end{array}$ & $\begin{array}{l}\text { Нафталанская } \\
\text { нефть } \\
\text { Naftalan oil }\end{array}$ & $\begin{array}{l}\text { Закавказская } \\
\text { Transcaucasian }\end{array}$ \\
\hline $\begin{array}{l}\text { Усинская нефть } \\
\text { Usinskaya oil }\end{array}$ & \begin{tabular}{|l} 
Тимано- \\
Печорская \\
Timan-Pechora
\end{tabular} & $\begin{array}{l}\text { Ж-1 } \\
\text { LP-1 }\end{array}$ & - \\
\hline $\begin{array}{l}\text { Нефть } \\
\text { Ляохэ }\end{array}$ & $\begin{array}{l}\text { Liaohe oil Bohai } \\
\text { Gulf }\end{array}$ & $\begin{array}{l}\text { ЖП-2 } \\
\text { LP-2 }\end{array}$ & - \\
\hline $\begin{array}{l}\text { Нефть Хаудаг } \\
\text { Haudag oil }\end{array}$ & \begin{tabular}{|l} 
Таджикская \\
депрессия \\
Tajik Depression
\end{tabular} & $\begin{array}{l}\text { ЖП-3 } \\
\text { LP-3 }\end{array}$ & - \\
\hline $\begin{array}{l}\text { Ай-Яунская } \\
\text { нефть } \\
\text { Ai-Yaunskaya } \\
\text { oil }\end{array}$ & $\begin{array}{l}\text { Западно- } \\
\text { Сибирская } \\
\text { West Siberian }\end{array}$ & $\begin{array}{l}\text { Северная нефть } \\
\text { (скв. 564) } \\
\text { Severnaya oil } \\
\text { (well 564) }\end{array}$ & \multirow{3}{*}{$\begin{array}{l}\text { Западно- } \\
\text { Сибирская } \\
\text { West Siberian }\end{array}$} \\
\hline $\begin{array}{l}\text { Ашальчинская } \\
\text { мальта } \\
\text { Ashalchinskaya } \\
\text { malta }\end{array}$ & $\begin{array}{l}\text { Волго- } \\
\text { Уральская } \\
\text { Volga-Ural }\end{array}$ & $\begin{array}{l}\text { Северная нефть } \\
\text { (скв. 389) } \\
\text { Severnaya oil } \\
\text { (well 389) }\end{array}$ & \\
\hline $\begin{array}{l}\text { Биодеградиро- } \\
\text { ванная ашаль- } \\
\text { чинская мальта } \\
\text { Biodegradated } \\
\text { Ashalchinskaya } \\
\text { malta }\end{array}$ & - & $\begin{array}{l}\text { Северная нефть } \\
\text { (скв. 254) } \\
\text { Severnaya oil } \\
\text { (well 254) }\end{array}$ & \\
\hline $\begin{array}{l}\text { Ван-Еганская } \\
\text { нефть } \\
\text { Van-Egan oil }\end{array}$ & $\begin{array}{l}\text { Западно- } \\
\text { Сибирская } \\
\text { West Siberian }\end{array}$ & $\begin{array}{l}\text { Самотлорская } \\
\text { нефть } \\
\text { Samotlorskaya } \\
\text { oil }\end{array}$ & $\begin{array}{l}\text { Западно- } \\
\text { Сибирская } \\
\text { West Siberian }\end{array}$ \\
\hline
\end{tabular}

НГО - нефтегазоносная область; НГП - нефтегазоносная про виниия; ЖП-1, 2, 3 - жидкие продукты СКВ конверсии Ивановско20 асфальтита.

НГО - Oil-and-gas region; НГП - Oil-and-gas province; LP-1, 2, 3 liquid products of SCW conversion of Ivanovsky asphaltite.

Пиролитический анализ образцов был выполнен на установке «Rock-Eval 6 Turbo» [16] французской фирмы VINCI Technologies. Образцы в количестве 10-15 мг наносили на прокаленный при $800{ }^{\circ} \mathrm{C}$ песчаник и анализировали с использованием стадии «пиролиз» в цикле «Reservoir». Особенность этого цикла заключается в низкой начальной температуре пиролиза $\left(180^{\circ} \mathrm{C}\right)$. Образец выдерживали при начальной температуре 10 минут.
В течение этого времени формируется пик $S 1$. Дальнейший нагрев от 180 до $650{ }^{\circ} \mathrm{C}$ со скоростью $25^{\circ} \mathrm{C} /$ мин позволяет получить пики $S 2 \mathrm{a}$ и $S 2 \mathrm{~b}$. В процессе анализа определяли количество органических соединений, выделившихся в области соответствующих пиков $\left(S_{1}, S_{2 \mathrm{a}}, S_{2 \mathrm{~b}}\right)$, а также температуры максимальной скорости выхода углеводородов (TpS2a, TpS2b) в пиках $S 2 \mathrm{a}$ и $S 2 \mathrm{~b}$.

\section{Результаты и их обсуждение}

Как следует из табл. 2, выбранные объекты существенно отличаются по компонентному составу. Суммарное содержание САВ в них варьирует в пределах $9,08 . . .81,84 \%$. Наибольшим суммарным содержанием САВ характеризуются твердые разновидности природных битумов: Ивановский асфальтит $(81,84 \%)$ и Оленекский асфальт $(63,76 \%)$. Промежуточное положение по содержанию САВ занимают тяжелые высоковязкие нефти Ляохэ $(46,19 \%)$, Хаудаг $(35,60 \%)$, Усинского $(30,40 \%)$, Ай-Яунского $(27,24 \%)$, месторождений и мальта Ашальчинского месторождения $(36,90$ \% ). Остальные нефти и продукты СКВ конверсии ивановского асфальтита характеризуются гораздо более низким суммарным содержанием CAB $(5,90 \ldots 15,43 \%)$.

Из табл. 2 также следует, что содержание серы в изученных образцах варьирует в широких пределах: от 0,37 до 6,23\%, что охватывает все четыре класса нефти согласно классификации, приведенной в [22], а именно малосернистая, сернистая, высокосернистая и особо высокосернистая. Для всех образцов масел не исключено наличие среди структурных фрагментов алифатических сульфидных мостиков. Масла также заметно отличаются атомным отношением $\mathrm{H} / \mathrm{C}(1,45 . . .1,75)$, которое характеризует относительное содержание в них алифатических, нафтеновых и ароматических соединений.

Результаты определения относительного содержания протонов в различных структурных фрагментах масел нефтей и природных битумов (табл. 3) свидетельствуют о том, что их доля в ароматических циклах молекул масел сравнительно невелика $(4,00 \ldots 5,94$ \% ). Для масел биодеградированной в лабораторных условиях Ашальчинской мальты она еще меньше - 3,87 \% . Для масел, выделенных из продуктов СКВ-конверсии Ивановского асфальтита (МЖП-1, 2, 3) [19], характерно явно более высокое содержание протонов в ароматических циклах $(7,6 . .10,0 \%)$ и появление небольшого количества $(0,1 . . .0,2 \%)$ олефинов.

Отношение $H_{\beta} / H_{\gamma}$, которое может отражать длину алкильных заместителей или степень их разветвленности, у изученных образцов природного происхождения отличается почти в 1,5 раза (от 1,68 до $3,05)$. Отношение $H_{\alpha} / H_{\mathrm{ar}}$, которое при прочих равных условиях должно возрастать при увеличении числа заместителей в ароматических циклах и снижаться при увеличении их конденсированности, отличается почти в 2 раза (от 1,60 до 2,98 ). 
Таблииа 2. Состав изученных нефтей, природных битумов и масел Table 2. Composition of crude oils, natural bitumens and their oils

\begin{tabular}{|c|c|c|c|c|c|c|}
\hline \multirow[t]{2}{*}{$\begin{array}{l}\text { Образец } \\
\text { Sample }\end{array}$} & \multicolumn{3}{|c|}{$\begin{array}{c}\text { Содержание } \\
\text { компонентов, \% } \\
\text { Component } \\
\text { percentage, } \%\end{array}$} & \multicolumn{2}{|c|}{$\begin{array}{c}\text { Содержание } \\
\text { элементов } \\
\text { в маслах, \% } \\
\text { Percentage of ele- } \\
\text { ments in oils, \% }\end{array}$} & \multirow[t]{2}{*}{$\begin{array}{l}(\mathrm{H} / \mathrm{C})_{\text {ar }} \\
(\mathrm{H} / \mathrm{C})_{\text {at }}\end{array}$} \\
\hline & $\begin{array}{l}\mathrm{A} \\
\mathrm{A}\end{array}$ & $\begin{array}{l}\text { СЭБ } \\
\text { EВR }\end{array}$ & $\begin{array}{c}\mathrm{M} \\
0\end{array}$ & $\mathrm{~N}$ & S & \\
\hline $\begin{array}{l}\text { Ивановский acфальтит } \\
\text { Ivanovsky asphaltite }\end{array}$ & 69,15 & 12,69 & 18,16 & 0,46 & 6,23 & 1,47 \\
\hline $\begin{array}{c}\text { Ай-Яунская нефть } \\
\text { Ai-Yaunskaya oil }\end{array}$ & 3,96 & 23,28 & 72,76 & 0,06 & 1,38 & 1,64 \\
\hline $\begin{array}{c}\text { Ашальчинская мальта } \\
\text { Ashalchinskaya malta }\end{array}$ & 6,20 & 26,20 & 67,20 & 0,07 & 3,83 & 1,61 \\
\hline $\begin{array}{c}\text { Нефть Хаудаг } \\
\text { Haudag oil }\end{array}$ & 6,60 & 29,00 & 64,40 & Н.д. & Н.д. & Н.д. \\
\hline $\begin{array}{c}\text { Нефть Ляохэ } \\
\text { Liaohe oil }\end{array}$ & 11,37 & 34,82 & 53,81 & 0,39 & 0,37 & 1,64 \\
\hline $\begin{array}{c}\text { Ван-Еганская нефть } \\
\text { Van-Egan oil }\end{array}$ & 0,11 & 14,63 & 85,26 & 0,11 & 1,08 & 1,58 \\
\hline $\begin{array}{c}\text { Биодеградированная } \\
\text { ашальчинская мальта } \\
\text { Biodegradated } \\
\text { Ashalchinskaya malta }\end{array}$ & Н.д. & Н.д. & Н.д. & 0,43 & 1,50 & 1,55 \\
\hline $\begin{array}{c}\text { Усинская нефть } \\
\text { Usinskaya oil }\end{array}$ & 11,22 & 19,14 & 69,64 & 0,34 & 1,85 & 1,62 \\
\hline $\begin{array}{c}\text { Оленекский acфальт } \\
\text { Oleneksky asphalt }\end{array}$ & 31,68 & 32,08 & 36,24 & 0,43 & 2,45 & 1,55 \\
\hline $\begin{array}{c}\text { Русская нефть } \\
\text { Russkaya oil }\end{array}$ & 2,07 & 12,71 & 85,22 & 0,06 & 0,68 & 1,62 \\
\hline $\begin{array}{c}\text { Нафталанская нефть } \\
\text { Naftalan oil }\end{array}$ & 0,43 & 8,65 & 90,92 & 0,05 & 0,54 & 1,61 \\
\hline $\begin{array}{c}\text { ЖП-1 } \\
\text { LP-1 }\end{array}$ & 14,2 & 19,8 & 66,0 & 0,80 & 5,04 & 1,49 \\
\hline $\begin{array}{l}\text { ЖH }-3 \\
\text { LP-3 }\end{array}$ & 5,80 & 9,90 & 84,3 & 0,60 & 4,07 & 1,46 \\
\hline $\begin{array}{c}\text { ЖП-2 } \\
\text { LP-2 }\end{array}$ & 5,10 & 11,00 & 83,9 & 0,62 & 4,80 & 1,45 \\
\hline $\begin{array}{l}\text { Северная нефть (скв. 389) } \\
\text { Severnaya oil (well 389) }\end{array}$ & 0,42 & 9,06 & 90,52 & 0,29 & 0,55 & 1,68 \\
\hline $\begin{array}{l}\text { Северная нефть (скв. 254) } \\
\text { Severnaya oil (well 254) }\end{array}$ & 1,00 & 8,86 & 90,14 & 0,30 & 0,50 & 1,73 \\
\hline $\begin{array}{l}\text { Северная нефть (скв. 564) } \\
\text { Severnaya oil (well 564) }\end{array}$ & 0,33 & 12,48 & 87,19 & 0,34 & 0,50 & 1,75 \\
\hline $\begin{array}{c}\text { Самотлорская нефть } \\
\text { Samotlorskaya oil }\end{array}$ & 0,70 & 5,20 & 94,10 & 0,30 & 0,61 & 1,60 \\
\hline
\end{tabular}

А - асфальтены, СЭБ - слоль этанол-бензольные, $M-$ масла. H.д. - нет данных.

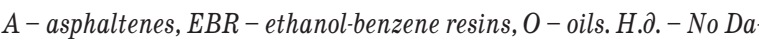
ta Available.

Таким образом, представленные результаты, в какой-то мере характеризующие состав изученных образцов масел, свидетельствуют о его различии. Можно было ожидать, что это различие найдет отражение в параметрах их термической устойчивости, которые определяются при пиролитическом анализе методом Rock-Eval. Полученные результаты представлены в табл. 4 и на рис. 1-4.

Пирограммы изученных образцов масел содержат три пика: $S 1, S 2$ a и $S 2 b$, проявляющиеся в различных температурных пределах (рис. 1). Пик $S 1$ (изотерма $180^{\circ} \mathrm{C}$ ) соответствует процессу испарения легких компонентов (бензиновой фракции $\left.\mathrm{H \kappa}-180{ }^{\circ} \mathrm{C}\right)$. Выход бензиновой фракции масел $\left(S_{1}\right)$ у изученных образцов варьирует в интервале
$42,1 \ldots 341,2$ мг/г. Пик $S 2 \mathrm{a}\left(180 \ldots 350^{\circ} \mathrm{C}\right)$, исходя из сущности метода Rock-Eval, соответствует наложению процесса испарения "средних» фракций масел и деструкции «слабых» $\mathrm{C}-\mathrm{S}, \mathrm{C}-\mathrm{O}$ связей в структурных фрагментах компонентов масел.

Таблица 3. Относительное содержание протонов в различных структурных фрагментах масел

Table 3. Relative content of protons in different structural fragments of oils

\begin{tabular}{|c|c|c|c|c|c|c|}
\hline \multirow{2}{*}{$\begin{array}{l}\text { Образец } \\
\text { Sample }\end{array}$} & \multicolumn{4}{|c|}{ Содержание, \% отн./Percentage, \% rel. } & \multirow{2}{*}{$H_{\alpha} / H_{\mathrm{ar}}$} & \multirow{2}{*}{$H_{\beta} / H_{\gamma}$} \\
\hline & $H_{\text {ar }}$ & $H_{\alpha}$ & $H_{\beta}$ & $H_{\gamma}$ & & \\
\hline $\begin{array}{l}\text { МИА } \\
\text { OIA }\end{array}$ & 5,50 & 15,50 & 58,00 & 21,00 & 2,82 & 2,76 \\
\hline $\begin{array}{l}\text { MAЯH } \\
\text { OAYO }\end{array}$ & 4,74 & 9,15 & 62,02 & 24,08 & 1,93 & 2,58 \\
\hline $\begin{array}{l}\text { MAM } \\
\text { OAM }\end{array}$ & 4,47 & 13,32 & 59,43 & 22,78 & 2,98 & 2,61 \\
\hline $\begin{array}{l}\text { MHX } \\
\text { OHO }\end{array}$ & 4,18 & 10,39 & 64,32 & 21,10 & 2,10 & 3,05 \\
\hline $\begin{array}{l}\text { MHJI } \\
\text { OLO }\end{array}$ & 4,18 & 9,16 & 54,33 & 32,33 & 2,19 & 1,68 \\
\hline $\begin{array}{l}\text { MBEH } \\
\text { OVEO }\end{array}$ & 5,11 & 10,55 & 59,65 & 24,69 & 2,07 & 2,42 \\
\hline $\begin{array}{c}\text { МАМ-БИО } \\
\text { ОАМ-ВI0 }\end{array}$ & 3,87 & 8,11 & 61,30 & 26,66 & 2,10 & 2,30 \\
\hline $\begin{array}{c}\text { MУH } \\
\text { OUO }\end{array}$ & 4,89 & 10,71 & 56,82 & 27,58 & 2,19 & 2,06 \\
\hline $\begin{array}{l}\text { MOA } \\
\text { OOA }\end{array}$ & 5,94 & 11,82 & 53,15 & 29,09 & 1,99 & 1,83 \\
\hline $\begin{array}{l}\text { MPH } \\
\text { ORO }\end{array}$ & 4,00 & 8,84 & 60,82 & 26,34 & 2,21 & 2,31 \\
\hline $\begin{array}{l}\text { MHH } \\
\text { ONO }\end{array}$ & 4,11 & 8,14 & 61,31 & 26,44 & 1,98 & 2,32 \\
\hline $\begin{array}{c}\text { МЖП-1 } \\
\text { OLР-1 }\end{array}$ & 7,60 & 15,6 & 58,90 & 17,8 & 2,05 & 3,31 \\
\hline $\begin{array}{c}\text { MЖП-3 } \\
\text { OLP-3 }\end{array}$ & 9,20 & 16,2 & 55,40 & 19,2 & 1,76 & 2,89 \\
\hline $\begin{array}{c}\text { MЖП-2 } \\
\text { OLР-2 }\end{array}$ & 10,00 & 15,9 & 57,00 & 17,0 & 1,59 & 3,35 \\
\hline $\begin{array}{c}\text { MCH-389 } \\
\text { OSO-389 }\end{array}$ & 5,41 & 9,30 & 60,38 & 24,91 & 1,72 & 2,42 \\
\hline $\begin{array}{c}\text { MCH-254 } \\
\text { OSO-254 }\end{array}$ & 5,28 & 9,26 & 59,68 & 25,77 & 1,75 & 2,32 \\
\hline $\begin{array}{c}\mathrm{MCH}-564 \\
\text { OSO-564 }\end{array}$ & 4,89 & 8,53 & 62,91 & 23,64 & 1,74 & 2,66 \\
\hline $\begin{array}{l}\text { MCaмH } \\
\text { OSam0 }\end{array}$ & 5,06 & 8,08 & 62,15 & 24,71 & 1,60 & 2,52 \\
\hline
\end{tabular}

МИА - масла Ивановского асфальтита; МАЯН - масла Ай-Яунской нефти; МАМ, МАМ-БИО - масла исходной и биодеградированной Ашальчинской мальты; МНХ - масла нефти Хаудаг; МНЛ - масла нефти Ляохэ; МВЕН - масла Ван-Еганской нефти; МУН - масла Усинской нефти; МОА - масла Оленекского асфальта; МРН - масла Русской нефти; МНH - масла Нафталанской нефти; МЖП-1, 2, 3 - масла жидких продуктов СКВ конверсии Ивановского асфальтита; МСН-389, 254, 564 - масла Северной нефти (иифры соответствуют номеру скважин); МСамН - масла Самотлорской нефти.

OIA - Oils of Ivanovsky asphaltite; OAYO - Oils of Ai-Yaunskaya oil; OAM, OAM-BIO - Oils of initial and biodegradated Ashalchinskaya malta; OHO - Oils of Haudag oil; OLO - Oils of Liaohe oil; OVEO Oils of Van-Egan oil; OUO - Oils of Usinskaya oil; OOA - Oils of Oleneksky asphalt; ORO - Oils of Russkaya oil; ONO - Oils of Naftalan oil; OLP-1, 2, 3-Oils of liquid products of SCW conversion of Ivanovsky asphaltite; OSO-389, 254, 564 - Oils of Severnaya oil (wells 389, 254, 564); OSamO - Oils of Samotlorskaya oil. 
Tаблииа 4. Результаты Rock-Eval анализа масел

Table 4. Data of Rock-Eval analysis of oils

\begin{tabular}{|c|c|c|c|c|c|c|c|c|}
\hline \multirow{2}{*}{$\begin{array}{c}\text { Образец } \\
\text { Sample }\end{array}$} & $S_{1}$ & $S_{2 \mathrm{a}}$ & $S_{2 \mathrm{~b}}$ & $T p S 2 \mathrm{a}$ & $T p S 2 \mathrm{~b}$ & \multirow{2}{*}{$\begin{array}{c}S_{2 \mathrm{a}}+S_{2 \mathrm{~b}}, \\
\mathrm{M \Gamma} / \Gamma \\
(\mathrm{mg} / \mathrm{g})\end{array}$} & \multirow{2}{*}{ 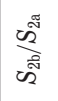 } & \multirow{2}{*}{ 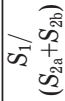 } \\
\hline & \multicolumn{3}{|c|}{ Мг/Г (mg/g) } & \multicolumn{2}{|c|}{${ }^{\circ} \mathrm{C}$} & & & \\
\hline \multicolumn{9}{|c|}{ Группа I/Group I: $\left(S_{2 \mathrm{~b}} / S_{2 \mathrm{a}}>1,0\right)$} \\
\hline $\begin{array}{c}\text { МИА } \\
\text { OIA }\end{array}$ & 62,1 & 191,2 & 746,7 & 350 & 466 & 937,9 & 3,91 & 0,066 \\
\hline $\begin{array}{l}\text { MAЯH } \\
\text { OAYO }\end{array}$ & 77,8 & 332,5 & 589,6 & 350 & 461 & 922,2 & 1,77 & 0,084 \\
\hline $\begin{array}{l}\text { MAM } \\
\text { OAM }\end{array}$ & 135,6 & 330,3 & 534,1 & 350 & 454 & 864,4 & 1,62 & 0,157 \\
\hline $\begin{array}{l}\text { MHX } \\
\text { OHO }\end{array}$ & 154,4 & 325,6 & 520,0 & 350 & 462 & 845,6 & 1,60 & 0,183 \\
\hline $\begin{array}{l}\text { MHJ } \\
\text { OLO }\end{array}$ & 84,6 & 366,1 & 549,2 & 350 & 456 & 915,4 & 1,50 & 0,092 \\
\hline $\begin{array}{l}\text { MBEH } \\
\text { OVEO }\end{array}$ & 83,8 & 390,9 & 525,3 & 350 & 456 & 916,2 & 1,34 & 0,091 \\
\hline $\begin{array}{c}\text { МАМ-БИО } \\
\text { ОАМ-ВІО }\end{array}$ & 42,1 & 428,5 & 529,5 & 350 & 450 & 957,9 & 1,24 & 0,044 \\
\hline $\begin{array}{c}\text { MУH } \\
\text { OUO }\end{array}$ & 170,5 & 382,2 & 447,4 & 340 & 449 & 829,5 & 1,17 & 0,205 \\
\hline $\begin{array}{l}\text { MOA } \\
\text { OOA }\end{array}$ & 126,5 & 509,5 & 364,0 & 342 & 445 & 873,5 & 1,17 & 0,145 \\
\hline $\begin{array}{l}\text { MPH } \\
\text { ORO }\end{array}$ & 71,3 & 441,4 & 487,3 & 343 & 450 & 928,7 & 1,10 & 0,077 \\
\hline \multicolumn{9}{|c|}{ Группа II/Group II: $S_{2 \mathrm{~b}} / S_{2 \mathrm{a}}=(0,5 \ldots 1,0)$} \\
\hline $\begin{array}{l}\text { MHH } \\
\text { ONO }\end{array}$ & 90,7 & 467,5 & 441,8 & 334 & 460 & 909,3 & 0,95 & 0,100 \\
\hline $\begin{array}{c}\text { MЖП-1 } \\
\text { OLP-1 }\end{array}$ & 163,6 & 443,1 & 393,3 & 328 & 450 & 836,4 & 0,89 & 0,196 \\
\hline $\begin{array}{c}\text { MЖП-3 } \\
\text { OLP-3 }\end{array}$ & 175,7 & 526,5 & 297,8 & 328 & 450 & 824,3 & 0,57 & 0,213 \\
\hline \multicolumn{9}{|c|}{ Группа III/Group III: $\left(S_{2 \mathrm{~b}} / S_{2 \mathrm{a}}<0,5\right)$} \\
\hline $\begin{array}{c}\text { MЖП-2 } \\
\text { OLР-2 }\end{array}$ & 159,6 & 570,8 & 269,6 & 318 & 450 & 840,4 & 0,47 & 0,190 \\
\hline $\begin{array}{c}\text { MCH-389 } \\
\text { OSO-389 }\end{array}$ & 278,2 & 494,1 & 227,8 & 314 & 450 & 721,8 & 0,46 & 0,385 \\
\hline $\begin{array}{c}\mathrm{MCH}-254 \\
\text { OSO-254 }\end{array}$ & 291,6 & 487,1 & 221,3 & 302 & 450 & 708,4 & 0,45 & 0,412 \\
\hline $\begin{array}{c}\text { MCH-564 } \\
\text { OSO-564 }\end{array}$ & 326,1 & 494,7 & 179,2 & 292 & 450 & 673,9 & 0,36 & 0,484 \\
\hline $\begin{array}{l}\text { MCamH } \\
\text { OSam0 }\end{array}$ & 341,2 & 499,6 & 159,2 & 294 & 450 & 658,8 & 0,32 & 0,518 \\
\hline \multicolumn{9}{|c|}{ Влияние биодеградации/Effect of biodegradation } \\
\hline $\begin{array}{l}\text { MAM } \\
\text { OAM }\end{array}$ & 135,6 & 330,3 & 534,1 & 350 & 454 & 864,4 & 1,62 & 0,157 \\
\hline $\begin{array}{c}\text { МАМ-БИО } \\
\text { ОАМ-ВІО }\end{array}$ & 42,1 & 428,5 & 529,5 & 350 & 450 & 957,9 & 1,24 & 0,044 \\
\hline \multicolumn{9}{|c|}{ Влияние конверсии в СКВ/Effect of SCW conversion } \\
\hline $\begin{array}{c}\text { МИА } \\
\text { ОIA }\end{array}$ & 62,1 & 191,2 & 746,7 & 350 & 466 & 937,9 & 3,91 & 0,066 \\
\hline $\begin{array}{c}\text { MЖП-1 } \\
\text { OLP-1 }\end{array}$ & 163,6 & 443,1 & 393,3 & 328 & 450 & 836,4 & 0,89 & 0,196 \\
\hline $\begin{array}{c}\text { МЖП-3 } \\
\text { 0LР-3 }\end{array}$ & 175,7 & 526,5 & 297,8 & 328 & 450 & 824,3 & 0,57 & 0,213 \\
\hline $\begin{array}{c}\text { MЖП-2 } \\
\text { OLР-2 }\end{array}$ & 159,6 & 570,8 & 269,6 & 318 & 450 & 840,4 & 0,47 & 0,190 \\
\hline
\end{tabular}

$S_{1}-$ выход бензиновой фракиии $\left(H K-180^{\circ} \mathrm{C}\right)$ масел; $S_{2 \mathrm{a}}$ и $S_{2 \mathrm{~b}}-$ выход летучих продуктов термической деструкции образиа при 180...350 и $350 . . .550{ }^{\circ} \mathrm{C}$, соответственно; (TpS2a, TpS2b) - телпературы максимальной скорости выхода углеводородов в пиках $S 2 a$ u $S 2 b$.

$S_{1}$ is the yield of gasoline fraction of oils $\left(I B P-180^{\circ} \mathrm{C}\right) ; S_{2 a}$ and $S_{2 b}$ is the yield in volatile products of thermal destruction of the sample at $180 \ldots 350$ and $350 \ldots 650^{\circ} \mathrm{C}$, respectively; (TpS2a.TpS2b) are the tempera tures of maximum rate of release of hydrocarbon for $S 2 a$ and $S 2 b$ peaks.
Выход летучих продуктов из масел в области этого пика $\left(S_{2 \mathrm{a}}\right)$ у изученных образцов варьирует в интервале $191,2 \ldots 570,8$ мг/г. Пик $S 2 \mathrm{~b}\left(350 \ldots . .550{ }^{\circ} \mathrm{C}\right)$ соответствует наложению испарения «высококипящих» компонентов масел и деструкции «прочных» $\mathrm{C}-0, \mathrm{C}-\mathrm{C}$ связей в их структурных фрагментах. Выход летучих продуктов из масел в области этого пика $\left(S_{2 b}\right)$ у изученных образцов варьирует в интервале $159,2 \ldots 746,7$ мг/г.

Из характера пирограмм, представленных на рис. 1, следует, что для всех образцов полная деструкция достигается при $550{ }^{\circ} \mathrm{C}$. Из табл. 4 видно, что отношение выхода летучих продуктов в области пиков $S 2 \mathrm{~b}$ и $S 2 \mathrm{a}\left(S_{2 \mathrm{~b}} / S_{2 \mathrm{a}}\right)$ для изученных образцов отличается более чем на порядок и варьирует от 0,32 до 3,91 . По этому показателю изученные образцы могут быть разделены условно на группы I-III: $>1,0 ; 0,5 \ldots 1,0 ;<0,5$. Их типичные пирограммы представлены на рис. 1 . Минимальное значение $S_{1}$ и $S_{2 \mathrm{a}}$ характерно для образцов группы I, а максимальное - для образцов группы III. Для пика $S 2 b$ все наоборот: минимальное значение $S_{2 b}$ наблюдается у образцов группы III, а максимальное у образцов группы I. Как видно на рис. 2 , наблюдается функциональная связь отношения $S_{2 \mathrm{~b}} / S_{2 \mathrm{a}}$ с выходом бензиновой фракции масел $\left(S_{1}\right)$ : чем выше $S_{2 \mathrm{~b}} / S_{2 \mathrm{a}}$, тем ниже $S_{1}$.

При биодеградации отношение $S_{1} /\left(S_{2 \mathrm{a}}+S_{2 \mathrm{~b}}\right)$ резко снижается, а при СКВ конверсии резко возрастает, что вполне объяснимо. При биодеградации в первую очередь ассимилируются низкомолекулярные алканы состава $\mathrm{C}_{12}-\mathrm{C}_{20}$ [23]. А при СКВ конверсии асфальтита их доля в составе масел, напротив, возрастает [19].

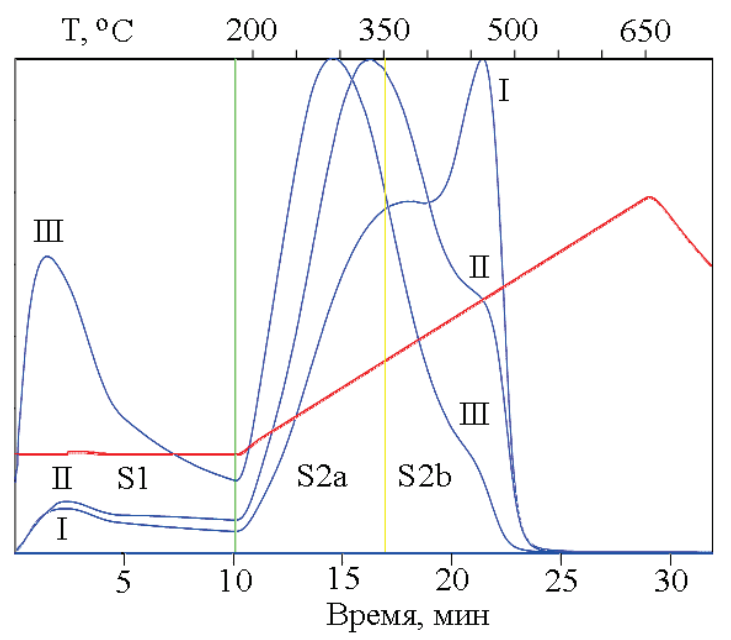

Pис.1. Типичные пирограммы для масел с различным отношением. $S_{2 b} / S_{2 a}$. I - >1,0; II - 0,5...1,0; III - <0,5. Красным температурная кривая

Fig. 1. Typical pyrograms for oils with different $S_{2 \mathrm{~b}} / S_{2 \mathrm{a}}$ ratios. $I->1,0 ; I I-0,5 \ldots 1,0 ; I I I-<0,5$. Temperature curve is highlighted in red

Температура максимальной скорости выхода углеводородов в области пика $S 2 \mathrm{~b}(T p S 2 \mathrm{~b})$, по-нашему мнению, отражающая энергию разрыва 
«прочных» связей, варьирует для всей совокупности образцов от 445 до $466^{\circ} \mathrm{C}$, причем, как следует из табл. 4 , это различие характерно, главным образом, для образцов группы І. Для большинства образцов группы II и для группы III в целом она одинакова $\left(450{ }^{\circ} \mathrm{C}\right)$.

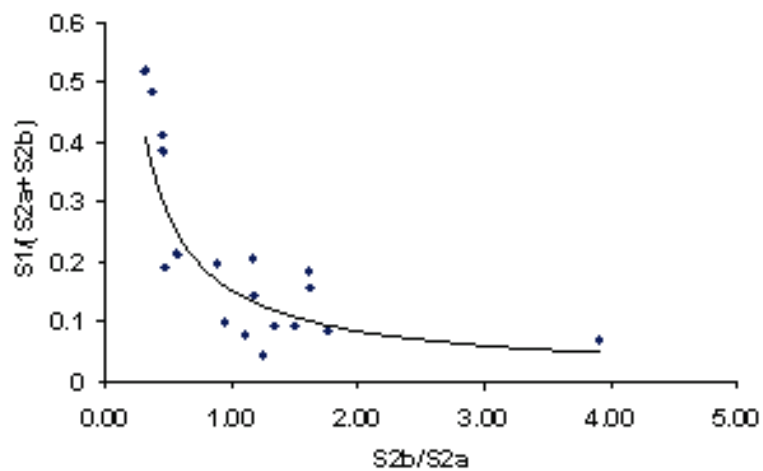

Pис. 2. Зависимость выхода бензиновой фракции масел $\left(S_{1}\right)$ от соотношения выхода летучих продуктов при $350 . .550$ u $180 \ldots 350^{\circ} \mathrm{C}\left(S_{2 \mathrm{~b}} / S_{2 \mathrm{a}}\right)$

Fig. 2. Yield of gasoline fraction of oils $\left(S_{1}\right)$ vs the ratio of the yield in volatile products at $350 \ldots 550$ and $180 \ldots 350{ }^{\circ} \mathrm{C}\left(S_{2 \mathrm{~b}} / S_{2 \mathrm{a}}\right)$

Температура максимальной скорости выхода углеводородов в области пика $S 2$ a (TpS2a), по-нашему мнению, отражающая энергию разрыва «слабых» связей, меняется в более широких пределах $\left(292 \ldots 350{ }^{\circ} \mathrm{C}\right) . T p S 2$ а при уменьшении отношения $S_{2 \mathrm{~b}} / S_{2 \mathrm{a}}$ в группе I снижается от 350 до $342{ }^{\circ} \mathrm{C}$, в группе II - от 334 до $328^{\circ} \mathrm{C}$, в группе III - от 318 до $292{ }^{\circ} \mathrm{C}$. Следует отметить, что в группе I при значении $S_{2 \mathrm{~b}} / S_{2 \mathrm{a}}>1,24 T p S 2 \mathrm{a}$ не меняется и составляет $350{ }^{\circ} \mathrm{C}$.

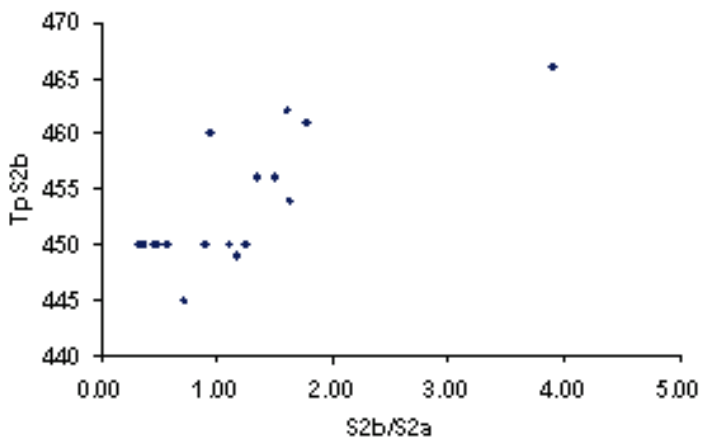

Puc. 3. Взаилосвлзь TpS2b и $S_{2 \mathrm{~b}} / S_{2 \mathrm{a}}$

Fig. 3. Relationship of TpS2b and $S_{2 \mathrm{~b}} / S_{2 \mathrm{a}}$

\section{СПИСОК ЛИТЕРАТУРЫ}

1. Ахметов С.А. Технология глубокой переработки нефти и газа. СПб.: Недра, 2013. - 541 с.

2. Капустин В.М., Гуреев А.А. Технология переработки нефти. Ч. 2: Деструктивные процессы. - М.: Колос, 2007. - 334 с.

3. Антипенко В.Р., Меленевский В.Н. Состав летучих продуктов фләш-пиролиза природного асфальтита, его смолисто-асфальтеновых и масляных компонентов // Нефтехимия. - 2012. T. 52. - № 6. - C. 403-412.

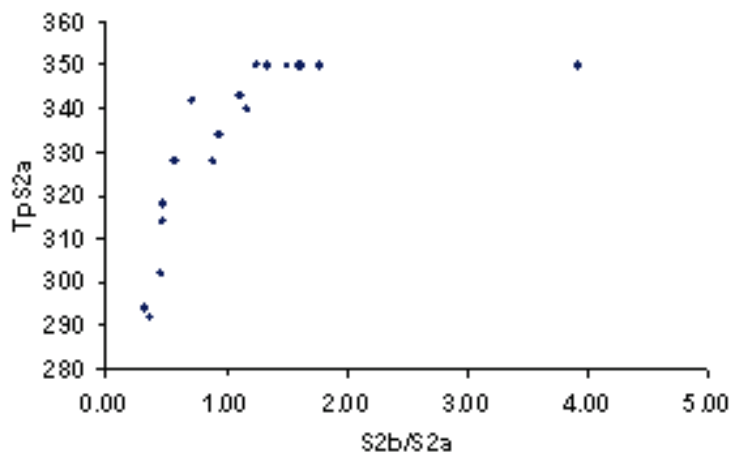

Puc. 4. Взаилосвязь TpS2a и $S_{2 \mathrm{~b}} / S_{2 \mathrm{a}}$

Fig. 4. Relationship of TpS2a and $S_{2 b} / S_{2 \mathrm{a}}$

\section{Заключение}

Таким образом, показано, что методом RockEval можно получить информацию о сравнительной термической устойчивости масел и характеристических температурах деструкции содержащихся в них компонентов для образцов, выделенных из нефтей и природных битумов, отобранных в различных нефтегазоносных провинциях и отличающихся компонентным составом. Пирограммы масел содержат три пика, проявляющихся в различных интервалах температур. Пик $S 1$ (изотерма $180{ }^{\circ} \mathrm{C}$ ) соответствует процессу испарения низкокипящих компонентов (бензиновой фракции $\left.\mathrm{HK}-180{ }^{\circ} \mathrm{C}\right)$. Пик $S 2 \mathrm{a}\left(180 \ldots 350{ }^{\circ} \mathrm{C}\right)$ соответствует наложению процесса испарения «средних» фракций масел и деструкции «слабых» $\mathrm{C}-\mathrm{S}, \mathrm{C}-0$ связей в структурных фрагментах их компонентов. Пик $S 2 \mathrm{~b}\left(350 \ldots 550{ }^{\circ} \mathrm{C}\right)$ соответствует наложению испарения «высококипящих» компонентов масел и деструкции «прочных» $\mathrm{C}-\mathrm{O}, \mathrm{C}-\mathrm{C}$ связей в их структурных фрагментах. Изученные образцы более чем на порядок (от 0,32 до 3,91 ) отличаются отношением выхода летучих продуктов при $350 \ldots 550{ }^{\circ} \mathrm{C}$ и $180 \ldots 350{ }^{\circ} \mathrm{C}\left(S_{2 b} / S_{2 a}\right)$, а также отношением выхода бензиновой фракции масел $\left(S_{1}\right)$ и $\left(S_{2 \mathrm{~b}}+S_{2 \mathrm{a}}\right)$ (от $0,044$ до 0,518$)$. Изученные образцы масел также отличаются по температуре максимальной скорости выхода углеводородов в области пика $S 2 \mathrm{~b}$ (от 466 до $445{ }^{\circ} \mathrm{C}$ ) и более существенно в области пика S2a (от 350 до $292^{\circ} \mathrm{C}$ ).

Полученные результаты могут учитываться при выборе оптимальных режимов термической и термокаталитической переработки тяжелого нефтяного сырья.

4. Состав «связанных» соединений в маслах биодеградированных нефтей по результатам их «on line» флэш-пиролиза / B.P. Антипенко, О.С. Баканова, В.Н. Меленевский, Е.А. Ельчанинова // Известия Томского политехнического университета. Инжиниринг георесурсов. - 2015. - Т. 326. - № 6. - С. 46-55.

5. Антипенко В.Р., Чешкова Т.В. Состав соединений, связанных через эфирные и сульфидные мостики в маслах природного битума Ашальчинского месторождения // Известия Томского политехнического университета. - 2014. - Т. 324. - № 3. - С. 16-21. 
6. Баканова 0.С., Антипенко В.Р. Новый подход к определению структуры фрагментов, связанных через әфирные мостики в маслах нефтей и природных битумов // Химия в интересах устойчивого развития. - 2018. - Т. 26. - № 1. - С. 109-114.

7. Энергии разрыва химических связей. Потенциалы ионизации и сродство к электрону / Л.В. Гурвич, Г.В. Карачевцев, В.Н. Кондратьев, Ю.А. Лебедев, В.А. Медведев, В.К. Потапов, Ю.С. Ходеев. - М.: Наука, 1974. - 351 с.

8. Espitalié J., Deroo G., Marquis F. La pyrolyse Rock-Eval et ses applications // Oil \& Gas Science and Technology. - 1985. V. 40. - № 5. - P. 563-579.

9. Peters K. Guidelines for evaluating petroleum source rock using programmed pyrolysis // American Association of Petroleum Geologists Bulletin. - 1986. - V. 70. - № 3. - P. 318-329.

10. Конторович А.Э., Меленевский В.Н., Борисова Л.С. Диагностика асфальтенов рассеянного органического вещества и нефтей пиролитическим методом // Докл. АН СССР. - 1988. T. 302. - № 3. - С. 700-703.

11. Lafargue E., Marquis F., Pillot D. Rock-Eval 6 Applications in Hydrocarbon Exploration, Production and Soils Contamination Studies // Oil \& Gas Science and Technology. - 1998. - V. 53. № 4. - P. 421-437.

12. Меленевский В.Н., Борисова Л.С., Тимошина И.Д. Пиролитическая характеристика твердых битумов ряда кериты-антраксолиты // Геология нефти и газа. - 2008. - № 4. - С. 40-45.

13. Диагенетическая трасформация органического вещества голоценовых осадков Черного моря по данным пиролиза / В.Н. Меленевский, С.В.Сараев, Е.А. Костырева, В.А. Каширцев // Геология и геофизика. - 2017. - Т. 58. - № 2. - С. 273-289.

14. Современный метод определения пиролитических параметров горных пород / Э.А. Вторушина, Т.Д. Булатов, И.В. Козлов,
М.Н. Вторушин // Геология нефти и газа. - 2018. - № 2. C. 71-77.

15. Guidelines for kinetic input to petroleum system models from open-system pyrolysis / K.E. Peters, A.K. Burnham, C.C. Walters, 0. Schenk // Marine and Petroleum Geology. - 2018. V. 92. - P. 979-986.

16. Behar F., Beaumont V., De B Penteado H.L. Rock-Eval 6 Technology: Perfomances and Developments // Oil \& Gas Science and Technology - Rev. IFP. - 2001. - V. 56. - № 2. - P. 111-134.

17. $T_{\max }$ of asphaltenes: a parameter for oil maturity assessment / M. Nali, G. Caccialanza, C. Ghiselli, M.A. Chiaromonte // Organic Geochemistry. - 2000. - V. 31. - P. 1325-1332.

18. Биогенное окисление высоковязкой нефти Ашальчинского месторождения и ее гетероорганических соединений / Д.А. Филатов, Е.Б. Кривцов, Н.Н. Свириденко, А.К. Головко, Л.К. Алтунина // Нефтехимия. - 2017. - Т. 57. - № 4. - С. 386-393.

19. Fedyaeva 0.N., Antipenko V.R., Vostrikov A.A. Conversion of sulfur-rich asphaltite in supercritical water and effect of metal addition // The Journal of Supercritical Fluids. - 2014. - V. 88. P. 105-116.

20. Современные методы исследования нефтей (Справочно-методическое пособие) / под ред. А.И. Богомолова, М.Б. Темянко, Л.И. Хотынцевой. - Л.: Недра, 1984. - 431 с.

21. Speight J.G. Handbook of Petroleum Analysis. - New-York: Willey Interscience, 2001. $-489 \mathrm{p}$.

22. ГОСТ Р 51858-2002. Нефть. Общие технические условия. - М.: ИПК Изд-во стандартов, 2002. - 9 с.

23. Петров Ал.А. Углеводороды нефти. - М.: Наука, 1984. - 264 с.

Поступила 01.03.2019 2.

\section{Информация об авторах}

Антипенко B.P., доктор химических наук, профессор, ведущий научный сотрудник лаборатории гетероорганических соединений нефти Института химии нефти СО РАН.

Баканова O.C., аспирант лаборатории гетероорганических соединений нефти Института химии нефти СО PAH.

Kaшапов P.C., научный сотрудник лаборатории геохимии и пластовых нефтей ОАО «ТомскНИПИнефть». 
UDC 665.613: 543.57

\title{
CHARACTERISTICS OF THERMAL STABILITY OF OILS OF NATURAL BITUMENS AND CRUDE OILS
}

\author{
Vladimir R. Antipenko', \\ avr@ipc.tsc.ru \\ Olga S. Bakanova', \\ olgapushkar@mail.ru \\ Roman S. Kashapov², \\ KashapovRS@tomsknipi.ru \\ 1 Institute of Petroleum Chemistry SB RAS, \\ 4, Akademichesky avenue, Tomsk, 634055, Russia. \\ 2 Tomsk Oil and Gas Research and Design Institute («TomskNIPIneft», Joint Stock Company), \\ 72, Mira avenue, Tomsk, 634027, Russia.
}

The relevance of the research is caused by the fact that thermal destruction is one of the most common processes of refining oil residues, heavy oils, and natural bitumens. Thermal and thermocatalytic processes of conversion of the above mentioned hydrocarbon feedstocks are accompanied by formation of supplementary distillate fractions ("secondary» oils) during thermal degradation of resinasphaltene substances of initial objects. Transformation of oils of the initial object and "secondary» oils occurs simultaneously at temperatures corresponding to the thermal disruption of "weak» and "strong» bonds in their constituent compounds. When choosing the optimum modes of thermal and thermocatalytic processing of heavy oil feedstock, the results of assessment of thermal stability of its components should be taken into account. One of the methods for studying the thermal stability of sedimentary organic matter is the RockEval pyrolysis. Information about the potential of this method for analysis of oils is very limited. However, the information on their thermal stability and characteristic temperatures of destruction of their constituents could be obtained from the pyrogram of oils. The analysis of the pyrogram will also provide information on the difference in these parameters for oils isolated from crude oils and natural bitumens, sampled in various oil provinces and significantly differing in their component composition.

The main aim of the research is a comparative analysis of thermal stability of oils isolated from natural bitumens and crude oils differing in the total content of resin-asphaltene substances, products of their laboratory biodegradation and conversion in supercritical water using the Rock-Eval method.

Objects: oils isolated from 18 samples of crude oils and natural bitumens, products of their laboratory biodegradation and conversion in supercritical water.

Methods: elemental analysis, NMR' ${ }^{\prime} H$-spectroscopy, Rock-Eval pyrolytic analysis.

Results. It is shown that the information on thermal stability of oils isolated from crude oils and natural bitumens sampled in various oil provinces and differing in their component composition could be obtained via Rock-Eval pyrolysis. The presence of three peaks characteristic for oils is evident from the pyrograms. They are observed within different temperature ranges. Hence, S1 peak (isotherm $180^{\circ} \mathrm{C}$ ) corresponds to the process of the gasoline fraction (initial boiling point $(I B P) \ldots 180^{\circ} \mathrm{C}$ ) evaporation. The S2a peak $\left(180 . . .350^{\circ} \mathrm{C}\right)$ corresponds to overlapping of evaporation of intermediate fractions of oils and rupture of "weak» $C-S, C-O$ bonds in the structural fragments of their compounds. The $S 2 \mathrm{~b}$ peak $\left(350 . .550^{\circ} \mathrm{C}\right)$ corresponds to overlapping of evaporation of high-boiling fractions of oils and rupture of «strong» C-O, C-C bonds in their structural fragments. The samples under study differ by more than one order of magnitude (from $0,32$ to 3,91$)$ in the ratio of the yields in volatile products at $350 \ldots 550$ and $180 . .350{ }^{\circ} \mathrm{C}\left(S_{2 b} / S_{2 a}\right)$ and in the ratio of the yields in the gasoline fraction of oils $-S 1$ and $S_{2 b}+S_{2 a}(0,044$ to 0,518$)$. The samples of oils under study also differ in the temperature of maximum rate of release of hydrocarbons in the course of pyrolysis in the range of S2b peak (from 445 to $466{ }^{\circ} \mathrm{C}$ ). This difference is more significant in the range of the S2a peak (from 292 to $350^{\circ} \mathrm{C}$ ).

Key words:

Crude oils, natural bitumens, oils, isolation, composition, Rock-Eval-analysis, thermal stability.

\section{REFERENCES}

1. Akhmetov S.A. Tekhnologiya glubokoy pererabotki nefti i gaza [Technology of deep processing of oil and gas]. St-Peterburg, Nedra Publ., 2013. 541 p.

2. Kapustin V.M., Gureev A.A. Tekhnologiya pererabotki nefti. Ch. 2. Destruktivnye protsessy [Technology of oil processing. P. 2: Destructive processes]. Moscow, Kolos Publ., 2007. 334 p.

3. Antipenko V.R., Melenevskii V.N. Composition of volatile products of flash pyrolysis of natural asphaltite and its resin-asphaltene and oil components. Petroleum Chemistry, 2012, vol. 52, no. 6 , pp. 373-382.

4. Antipenko V.R., Bakanova O.S., Melenevskiy V.N., Elchaninova E.A. «Bonded» compounds composition in the oils of biodegradated petroleum using their «on-line» flash pyrolysis. Bulletin of the Tomsk Polytechnic University. Geo Assets Engineering, 2015, vol. 326, no. 6, pp. 46-55. In Rus.
5. Antipenko V.R., Cheshkova T.V. Composition of the compounds bonded via ether, ester and sulfide linkages in oils of natural bitumen from Ashalchinskoye deposit. Bulletin of the Tomsk Polytechnic University, 2014, vol. 324, no. 3, pp. 16-21. In Rus.

6. Bakanova O.S., Antipenko V.R. Novy podkhod k opredeleniyu struktury fragmentov, svyazannykh cherez efirnye mostiki v maslakh neftey i prirodnykh bitumov [New approach towards structure determination of fragments coupled via ether/ester bridges in petroleum and natural bitumen oils]. Khimiya $v$ interesakh ustoychivogo razuitiya, 2018, vol. 26, no. 1, pp. 109-114.

7. Gurvich L.V., Karachentsev G.V., Kondratiev V.N., Lebedev Yu.A., Medvedev V.A., Potapov V.K., Khodeev Yu.S. Energii razryva khimicheskikh svyazey. Potentsialy ionizatsii i srodstvo $k$ elektronu [Break Energies of Chemical Bonds. Ionization Potentials and Electron Affinity]. Moscow, Nauka Publ., 1974. $351 \mathrm{p}$. 
8. Espitalié J., Deroo G., Marquis F. La pyrolyse Rock-Eval et ses applications. Oil \& Gas Science and Technology, 1985, vol. 40, no. 5, pp. 563-579.

9. Peters K. Guidelines for evaluating petroleum source rock using programmed pyrolysis. American Association of Petroleum Geologists Bulletin, 1986, vol. 70, no. 3, pp. 318-329.

10. Kontorovich A.E., Melenevskiy V.N., Borisova L.S. Diagnostika asfaltenov rasseyannogo organicheskogo veshchestva i neftey piroliticheskim metodom [Diagnostics of asphaltenes in dispersed organic matter and oil by a pyrolytic method]. Doklady Akademii Nauk SSSR, 1988, vol. 302, no. 3, pp. 700-703.

11. Lafargue E., Marquis F., Pillot D. Rock-Eval 6 Applications in Hydrocarbon Exploration, Production and Soils Contamination Studies. Oil \& Gas Science and Technology, 1998, vol. 53, no. 4, pp. 421-437.

12. Melenevskiy V.N., Borisova L.S., Timoshina I.D. Pyrolytic characteristics of hard bitumen of kerite-anthraxolite series. Oil and gas geology, 2008, no. 4, pp. 40-45. In Rus.

13. Melenevskiy V.N., Saraev S.V., Kostyreva E.A., Kashirtsev V.A. Diagenetic transformation of organic matter of the Holocene Black Sea sediments according to pyrolysis data. Russian Geology and Geophysics, 2017, vol. 58, no. 2, pp. 273-289. In Rus.

14. Vtorushina E.A., Bulatov T.D., Kozlov I.V., Vtorushin M.N. The advanced technique for determination of pyrolysis parameters of rocks. Oil and gas geology, 2018, no. 2, pp. 71-77. In Rus.

15. Peters K.E., Burnham A.K., Walters C.C., Schenk 0. Guidelines for kinetic input to petroleum system models from open-system pyrolysis. Marine and Petroleum Geology, 2018, vol. 92, pp. 979-986.
16. Behar F., Beaumont V., De B Penteado H.L. Rock-Eval 6 Technology: Perfomances and Developments. Oil \& Gas Science and Technology. Rev.IFP, 2001, vol. 56, no. 2, pp. 111-134.

17. Nali M., Caccialanza G., Ghiselli C., Chiaromonte M.A. $T_{\max }$ of asphaltenes: a parameter for oil maturity assessment. Organic Geochemistry, 2000, vol. 31, pp. 1325-1332.

18. Filatov D.A., Krivtsov E.B., Sviridenko N.N., Golovko A.K., Altunina L.K. Biogenic oxidation of the high-viscosity oil of the Ashal'chinskoe field and its hetero compounds. Petroleum Chemistry, 2017, vol. 57, no. 8, pp. 649-656.

19. Fedyaeva O.N., Antipenko V.R., Vostrikov A.A. Conversion of sulfur-rich asphaltite in supercritical water and effect of metal addition. The Journal of Supercritical Fluids, 2014, vol. 88, pp. 105-116.

20. Souremennye metody issledovaniya neftey (Spravochno-metodicheskoe posobie) [A Manual of Modern Oil Investigation Techniques]. Eds. A.I. Bogomolov, M.B. Temyanko, L.I. Khotyntseva. Leningrad, Nedra Publ., 1984. 431 p.

21. Speight J.G. Handbook of Petroleum Analysis. New-York, Willey Interscience, 2001. $489 \mathrm{p}$.

22. GOST R 51858-2002. Neft. Obshchie tekhnicheskie usloviya [State Standard R 51858-2002. Crude petroleum. General spesifications]. Moscow, IPK Standart Publ., 2002.9 p.

23. Petrov Al.A. Uglevodorody nefti [Hydrocarbons of crude oil]. Moscow, Nauka Publ., 1984. 264 p.

Received: 1 March 2019.

\section{Information about the authors}

Vladimir R. Antipenko, Dr. Sc, professor, leading researcher, Institute of Petroleum Chemistry SB RAS.

Olga S. Bakanova, postgraduate student, Institute of Petroleum Chemistry SB RAS.

Roman S. Kashapov, researcher, Tomsk Oil and Gas Research and Design Institute. 